\title{
The Training of Dieticians: The Current Position
}

Miss R. Pybus (The Brick House, Wicken, Newport, Essex)

It is particularly satisfactory that the dietician's work is to be discussed from so many angles today, for this emphasizes the importance of developing the present training upon a wider basis than has been done in the past. This point of view has been uppermost in the discussions of the Committee of the British Dietetic Association during recent years, and I can confidently say that it is the earnest desire of that Committee to promote a more uniformly high standard of training for dieticians, and to equip them for work in the ever widening field of activity which has been opening up to the profession during the past few years.

I am not speaking this morning as a representative of the British Dietetic Association and the opinions which I put forward are not necessarily sponsored by that Committee, but I know that our Association will welcome constructive criticism from the experts who are here today, and it is to be hoped that some of the many influential members of The Nutrition Society may be able to help us in certain of our difficulties.

\section{The British Dietetic Association}

Perhaps some of the audience may be a little hazy as to the functions and constitution of the British Dietetic Association and its right to speak for the profession. This Association was formed in 1936 to co-ordinate the scattered members of a growing profession into an organized body. The Association has helped to establish a reasonably high standard of training, and to take steps to see that this standard is maintained. A sub-committee inspects any training centre wishing to be recognized by the Association, and visits hospitals and other institutions where practical experience is offered. Many hospitals and scientific and other bodies regard membership of the Association as an essential qualification for the dietician. In addition to full members the Association admits, as affiliate members, women doing useful work in the field of nutrition, but not possessing the qualifications required for full membership. The Association has also 43 honorary members. While training, dietetic students may become associate members, and so attend the general meetings of the Association. Branch meetings also are arranged.

The Association has an appointments secretary who is in contact with prospective employers and who notifies members of vacant posts. There is also a liaison officer to help to co-ordinate the training courses.

Full members are encouraged to register with the Board of Registration of Medical Auxiliaries, though this does not of course mean that they intend to confine their activities to the feeding of the sick.

\section{The Development of Dietetic Training Centres}

Many of the audience are familiar with the various methods of training which are available to dieticians in this country, but it is not surprising that there are others who find the position confusing, and who wonder why we have not a more uniform curriculum.

I think the current position could be more readily understood if I reviewed briefly the conditions under which the present courses came into being. 
About 1922-23 the significance of diet in the treatment and investigation of various metabolic disorders was being more generally recognized, and there was an increased demand by physicians for special diets for such cases. It fell to the lot of the ward sisters to undertake to prepare these diets and they were also called upon to give dietetic instruction to out-patients about their special diets. Some of these women realized the smallness of their dietetic knowledge and were anxious to learn more but, unfortunately, there was no training centre for dieticians in this country.

About 1924-26, thanks to the generosity of the Rockefeller Foundation, sisters from the London Hospital, from St. Thomas's and from the Royal Infirmary of Edinburgh, were enabled to go to the U.S.A. and Canada for intensive dietetic study and experience. These nurses were soon followed by others and by B.Sc. graduates who were interested in dietetics but who could not get the necessary experience at home.

I think that most of us went to America with the idea of enlarging our knowledge of dietetic treatment, and I know that I was astounded to find American dieticians firmly established, not only in all branches of hospital food service, but also in the Red Cross, in public health departments, schools, colleges, and even in hotels and various commercial firms.

Dieticians returned to this country full of enthusiasm and anxious to play their part in the various branches of dietetics which they had seen developing in America, but the only opening for their activities was in the special diet kitchens, which were being started in a few hospitals, and sometimes in the out-patient departments. Most physicians paid little attention to the diets which were served as a routine in their hospitals, and many of these institutions were content to carry on with the very limited dietary scales which had been drawn up some fifty years previously. There was therefore no demand for a catering dietician and there was no incentive to train in this branch of work.

The next step was the establishment of a six months' practical training for dieticians which was begun in the dietetic departments of certain hospitals. This six months' training was open to the B.Sc. graduate, to teachers of domestic science and to the trained nurse. It was soon found that this amount of practical work was quite inadequate without a more specialized preliminary training and, therefore, during the thirties, dietetic diploma courses were inaugurated at King's College of Household and Social Science, the Glasgow and West of Scotland College of Domestic Seience and the Royal Infirmary of Edinburgh. More recently a course has been started for state registered nurses at the Royal College of Nursing. These are still the only centres where dietetic diploma courses can be taken, though it is hoped that a new course will be opened at Ireeds General Infirmary next autumn.

The number of students qualifying from the existing training schools is quite inadequate to meet the present demand for dieticians. There are plenty of candidates coming forward but there are not enough centres to train them. The British Dietetic Association is most anxious to promote further courses including a new degree course in dietetics which would cover a period of four years and which would include the theoretical and practical training. In my opinion, one of the most serious hindrances to the training of more dieticians is the dearth of trained teachers, who are qualified to teach dietetics up to a really high standard in both the preliminary and diploma courses.

voL. 4,1946$]$ 


\section{The Need for Postgraduate Courses}

Dieticians who are engaged in teaching students should be given an opportunity for postgraduate study from time to time, so that their knowledge may be kept up-to-date. Indeed refresher courses are earnestly desired by a number of dieticians. It seems strange that, in spite of all the original work on nutrition which has been carried out in this country, dieticians must go to the U.S.A. for intensive postgraduate study. In this respect I feel sure that some members of The Nutrition Society could offer valuable suggestions, and perhaps some philanthropist would consider financing postgraduate courses.

\section{The Training of Dieticians}

The dietician's training consists of two parts:

Part I. The preliminary training which can be taken in a variety of ways and which covers a period of from 2 to 4 years.

Part II. The dietetic diploma course which takes from 1 year to 18 months, and which includes from 2 to 3 terms of theory followed by 6 months' practical experience in an approved hospital, though the large scale cookery experience can be obtained in other approved centres.

Part I may be taken through any of the following means:

(1) A University Degree in household and social science or in domestic science or in pure science, including physiology and chemistry. Three months' intensive cookery experience is required by these students before entrance to the King's College diploma course.

(2) The State Registration in Nursing, provided the candidate holds the school leaving certificate or its equivalent. An entrance examination in chemistry is required unless this subject is included in the school leaving certificate, and a higher standard is required for the King's College course.

(3) A Teacher's Diploma in Domestic Science (3 years). The requirements for chemistry are the same as those for the trained nurse. The Ministry of Labour has suspended this method of training for the present.

(4) An Institutional Management Diploma of not less than 2 years' duration at an approved college. The qualifications for chemistry and general education are the same as for the trained nurse. These students are not eligible for the diploma course at King's College.

Part II. The dietetic diploma course and the practical work may be taken at:

King's College of Household and Social Science

(1) London University Diploma in Dietetics open only to B.Sc. graduates.

(2) King's College Diploma in Dietetics. Open also to students having the qualifications outlined in sections (2) and (3) of Part I, provided a high standard in physiology and chemistry has been attained.

The diploma course consists of 2 terms' theory followed by 6 months' experience in a hospital approved by the British Dietetic Association. 


\section{The Royal Infirmary of Edinburgh}

This training for the diploma course is open to all the classes of students mentioned above and varies according to the preliminary training taken.

The diploma course covers a period of 18 months and includes:

Theoretical training; one term's cooking for nurses and B.Sc. graduates; 6 months in the dietetic department and a few weeks in the general kitchen and steward's office. Students are advised to obtain a further 6 to 8 weeks' experience in large scale cookery.

\section{The Glasgow and West of Scotland College of Domestic Science}

The diploma course in dietetics is open to students in all the sections mentioned above. One year's course is given at the College followed by 6 months in the dietetic department of a hospital approved by the British Dietetic Association.

\section{The Royal College of Nursing}

The diploma in dietetics is open only to State Registered nurses. It is a $1 \frac{1}{2}$ years' course including theory and practical training in a hospital dietetic department, and general kitchen experience.

\section{Subjects Included in the Diploma Courses \\ Normal Curriculum}

During the diploma courses the following subjects are taught unless already taken up to a sufficiently high standard in the preliminary training:

Cookery; elementary anatomy and biology; bacteriology, with special reference to food; physiology; in some cases hygiene and advanced biology; nutrition; budgeting; kitchen administration and catering; diet in disease, and the medical aspect of diseases treated by diet; infant feeding, practical and theoretical; knowledge of the social services.

The practical work given in hospital during the final four to six months includes tuition by the dietician, and experience in the calculation, preparation and service of special diets.

Advice is given to patients on the management of their diets at home and the students visit the patients in the wards. Attendance at infant welfare clinics is arranged at some hospitals.

\section{Out-patient Experience}

In my opinion all students should spend some weeks working in an out-patient department where they may have an opportunity of taking dietary histories, and of making a report on the adequacy of the patient's previous diet. In this way the students develop their critical faculties; they learn about the food value of common articles of diet, and they get an insight into the home conditions of the patients, discovering also their food preferences. It is not possible to make a detailed analysis of the diet in every case, but this method of teaching students is extremely valuable.

\section{Large Scale Cookery}

Experience in catering and large scale cookery is an aspect of the dietician's training which the British Dietetic Association is most anxious to improve. It would seem a simple matter to stipulate that student vor. 4,1946$]$ 
dieticians must all have this experience before obtaining their diploma. Unfortunately there are few centres where satisfactory experience can be given and this regulation must be enforced gradually as conditions improve.

Meantime it would be an advantage if the courses in institutional management, given in domestic science colleges, could include more large scale cookery and less of some other subjects for those students who intend to take up dietetics.

In order to meet the great domand for dietician caterers the British Dietetic Association is anxious to promote a short term policy by which women, who have taken a domestic science training, and who have held responsible catering posts in the Forces, would be given an intensive theoretical training and qualify for membership of the Association.

\section{Specialized Training}

It may be argued with regard to the regular training courses that not all students wish to take up the work of catering dietician, and that some are not interested in the medical aspect of dietetics. Their ultimate aim may be to do dietetic work in public health, dietary surveys, research, or industry. Why should such students spend four to six months in a hospital diet department and six to eight weeks doing large scale cookery? I am convinced that, at least for the present, all dieticians should spend some time in the dietetic department of a hospital and in learning to cook for large numbers, though I think it is desirable to lengthen the period of practical training in order to include other aspects of dietetics. No student can be certain where her ultimate interests will lie, and a knowledge of medical dietetics and of large scale cookery will prove an asset in any branch of work. Moreover, it is only in a diet kitchen that the student receives intensive teaching in dietary calculations and learns to deal easily with foods and food values. It should be noted that there are far more vacancies for dieticians in hospitals than in any other type of work.

Nevertheless, some changes in the present training are overdue. The time has come when the dietician's training should be of a more specialized nature and directed more to the study of nutrition and allied subjects, together with the acquisition of good practical experience. A high standard of training must be aimed at but, after many years' experience of students of dietetics, I am convinced that it is not merely the type of training which makes the successful dietician. Character, personality and natural ability are of equal importance.

Until recent years we have been afraid to train a student solely as a dietician for, when qualified, she might find herself without a job. It was, therefore, essential that she should, if necessary, be able to earn her living in other ways.

The picture is now very different, and the demand for dieticians far exceeds the supply. This increased demand is in no small measure due to Sir Jack Drummond, who has emphasized repeatedly the part which dieticians can play, not only in the hospital, but also in maintaining the health of the nation as a whole. 